\title{
Mechanisms of $\mathrm{TiB}_{2}$ and graphite nucleation during $\mathrm{TiC}-\mathrm{B}_{4} \mathrm{C}$ high temperature interaction
}

\author{
O. Popov ${ }^{1}$, S. Chornobuk ${ }^{1}$, I. Totsky ${ }^{1}$, I. Plyushchay ${ }^{1}$, V. Vishnyakov ${ }^{2}$ \\ ${ }^{1}$ Faculty of Physics, Taras Shevchenko National University of Kiev, Hlushkov Ave. 4, Kiev \\ 03187, Ukraine \\ ${ }^{2}$ Institute for Materials Research, University of Huddersfield, HD1 3DH, UK
}

\begin{abstract}
Reactive hot pressing of $\mathrm{TiC}-\mathrm{B}_{4} \mathrm{C}$ precursors was undertaken at $1800{ }^{\circ} \mathrm{C}$ to produce $\mathrm{TiB}_{2}$ with carbon inclusions. Atomic mechanisms of titanium diboride nucleation, as well as spongelike carbon inclusions and submicron platelets of graphite precipitation has been investigated. Precursor grain size, green body composition and synthesis time were varied to analyse phases transformation. Boron from $\mathrm{B}_{4} \mathrm{C}$ grain sublimation is shown to result in carbon-based foam formation. Ab-initio calculations confirm that the boron atoms accumulation on (111) TiC plains leads to tensile stress. The developed stress cleaves $\mathrm{TiC}$ grains and enhances further reaction. Most of carbon expelled from $\mathrm{TiC}$ during its transformation into $\mathrm{TiB}_{2}$ forms graphite platelets.
\end{abstract}

Key words: titanium boride, titanium carbide, hetero-modulus ceramics, reactive sintering, reaction mechanisms, inclusions, precipitation, graphite platelets. 


\section{Introduction}

Presence of graphite or hexagonal boron nitride phases in superhard and refractory carbides, nitrides and borides result in substantial increase of thermal shock resistance [1-3], and machinability [4-6], with no impediment of high temperature properties. Some penalty, associated with the soft phases to hardness and strength are considered to be a "fair price" for other gains. The inclusions positive influence has been demonstrated by numerous investigations of heteromodulus ceramics (HMC): $\mathrm{Si}_{3} \mathrm{~N}_{4}-\mathrm{BN}[5,6]$, TiC-C [2, 7, 8], $\mathrm{B}_{4} \mathrm{C}-\mathrm{BN}[4,9], \mathrm{SiC}-\mathrm{BN}[10], \mathrm{TiB}_{2-}$ TiC-C [11], $\mathrm{ZrB}_{2}-\mathrm{SiC}-\mathrm{C}$ [12 - 15], $\mathrm{HfB}_{2}-\mathrm{HfC}-\mathrm{C}$ [16] and glass-BN [17]. Theoretical and experimental research, presented in all the mentioned studies, have showed that the influence of low-modulus phase on the material characteristics is closely related to sizes, shapes, and the distribution of the soft inclusions within the solid matrix. As it can be concluded from numerous works $[6,9,11,17,18]$, soft particles can not only "weaken" material but also improve its fracture resistance. This is achieved when cracks are arrested by blunting crack tips at low-E - high-E material interfaces. Achieving maximum of the interface area at the given and minimal low soft phase volume is therefore one of the most important directions of HMC structure optimization. As was shown in [18] the optimal interface/volume ratio can increase material toughness at least two fold. Moreover, effective optimization can be done with a specific architecture of ultra-fine, supposedly plate-like, soft inclusions evenly distributed inside the hard matrix.

One of the most valuable ways to create the mentioned ceramics is the reactive hot pressing of $\mathrm{TiC}-\mathrm{B}_{4} \mathrm{C}$ precursors [18]. The process bases on quick (for $1 \mathrm{~min}$ at $1800{ }^{\circ} \mathrm{C}$ [19]) precursor disappearance accompanied with $\mathrm{TiB}_{2}$ and graphite solid phase synthesizing. During the process, titanium diboride forms the material hard matrix, while graphite can be observed as (i) $2-4 \mu \mathrm{m}$ sponge-like areas or (ii) submicron platelets [18]. As is shown in [20], other transitional metal carbides can also interact with $\mathrm{B}_{4} \mathrm{C}$ in similar way. This paves the way of reactive sintering approach, which can be applied to sintering of various refractory systems. 
In order to maximize mechanical characteristics of such materials, one need to select sintering process and precursor composition in such a way that graphite phase segregates in the form of submicron platelets. At the same time, sponge-like soft graphite phase should be minimized. The particle shape and distribution optimization is impossible without the understanding of microscopic mechanisms of the phase formation process.

Hence, the main aim of the presented work is to uncover mechanisms of $\mathrm{TiB}_{2}$ and graphite nucleation and growth during the reaction:

$$
2 \mathrm{TiC}+\mathrm{B}_{4} \mathrm{C} \rightarrow 2 \mathrm{TiB}_{2}+3 \mathrm{C} .
$$

Bearing in mind reactive sintering of different $\mathrm{MeB}_{2}-\mathrm{C}$-based heteromodulus ceramics with preassigned composite structure and mechanical characteristics we will try to address the following questions:

- what is the cause of quick $\mathrm{TiC}$ to $\mathrm{TiB}_{2}$ solid phase transformation;

- where does the carbon move from a metal carbide being replaced with boron;

- how do carbon 'platelets' and 'sponges' form?

\section{Experimental}

Commercially available powders of $\mathrm{TiC}(\sim 70 \mu \mathrm{m}), \mathrm{TiC}(\sim 3 \mu \mathrm{m}), \mathrm{B}_{4} \mathrm{C}(\sim 60 \mu \mathrm{m})$ and $\mathrm{B}_{4} \mathrm{C}$ $(\sim 2 \mu \mathrm{m})$ (all of them produced by Donetsk Reactive Factory, Ukraine) were used as the green body materials. The material purity was at around 99.00 at $\%$. Material powders with big grains are later referred as "rough" and powders with small grains are referred as "fine". 
Table 1. Samples green body compositions and dwelling times at $1800{ }^{\circ} \mathrm{C}$

\begin{tabular}{|c|c|c|c|c|c|}
\hline$\#$ & $\begin{array}{c}\mathrm{TiC}(3 \mu \mathrm{m}), \\
\text { at. } \%\end{array}$ & $\begin{array}{c}\mathrm{TiC}(70 \mu \mathrm{m}), \\
\text { at.\% }\end{array}$ & $\begin{array}{c}\mathrm{B}_{4} \mathrm{C}(2 \mu \mathrm{m}), \\
\text { at. } \%\end{array}$ & $\begin{array}{c}\mathrm{B}_{4} \mathrm{C}(60 \mu \mathrm{m}), \\
\text { at.\% }\end{array}$ & $\mathrm{t}, \mathrm{min}$ \\
\hline 1.1 & 60 & - & - & 40 & 2 \\
\hline 1.2 & 60 & - & - & 40 & 4 \\
\hline 1.3 & 60 & - & - & 40 & 8 \\
\hline 1.4 & 60 & - & - & 40 & 16 \\
\hline 2.1 & - & 30 & 70 & - & 2 \\
\hline 2.2 & - & 30 & 70 & - & 8 \\
\hline 2.3 & - & 30 & 70 & - & 16 \\
\hline 2.4 & - & 30 & 70 & - & 2 \\
\hline 3.1 & 30 & - & 70 & - & 4 \\
\hline 3.2 & 30 & - & 70 & - & 16 \\
\hline 3.3 & 30 & - & 70 & - & 8 \\
\hline 3.4 & 30 & - & & & \\
\hline
\end{tabular}

The powder mixtures of three different composition sets (Table 1) were mixed in a planetary mill for 5 minutes and hot-pressed in a graphite die at $1800^{\circ} \mathrm{C}$ and $30 \mathrm{MPa}$. Maximum temperature isothermal dwelling time ranged between 2 and $16 \mathrm{~min}$. Sample compositions were chosen to provide the excess of one of the components. This was done to observe the process evolution of boron carbide $(1.1-1.4,3.1-3.4)$ and titanium carbide $(2.1-2.4)$ during sintering.

Crystalline phases in the sintered specimens were examined by X-Ray diffraction (XRD) (DRON-4M, St. Petersburg, Russia). Analysis of the microstructure and compositional analysis were performed with Scanning Electron Microscopy (SEM) and Energy Dispersive X-Ray Spectroscopy (EDX) (FEI Quanta 3D and Oxford Instruments INCA systems). For SEM and EDX analysis, samples were cleaved as this allowed to avoid polishing artefacts in material with great variation of constituent structures hardness. All SEM images presented in this work are taken with an electron backscatter detector (BSD) in so named Z-contrast mode. It means that the structures (grains) with the higher $\mathrm{Z}$ elements (and/or higher concentration of such elements) appear as the brighter areas on the images shown.

$\mathrm{Ab}$ initio calculation of boron impurities influence on $\mathrm{TiC}$ structure was carried out by density functional theory (DFT) in generalized gradient approximation (GGA) using ABINIT 
software package [22]. The annealing of the atomic positions was simulated according to the algorithm described in [23].

\section{The experimental results}

\subsection{Evolution of $\mathrm{B}_{4} \mathrm{C}$ during high temperature decomposition and mechanisms of} graphite sponge-like areas formation

The phase composition of samples \# 1.1 - 1.4 with grainy $\mathrm{B}_{4} \mathrm{C}$ and the excess of finer $\mathrm{TiC}$ particles in the green bodies was, as expected, changing with the sintering time by diminishing of boron and titanium carbides alongside with the gaining in $\mathrm{TiB}_{2}$ and graphite (See Fig. 1). It could be observed that: (i) boron carbide disappears between 4 and 8 minutes of the sintering and the process is accompanied by the most pronouncing change in $\mathrm{TiB}_{2}-\mathrm{TiC}$ ratio; (ii) while the reaction (1) is almost completed after 8 minutes, the distinct graphite peak appears only in XRD pattern of sample 1.4 (sintering time $16 \mathrm{~min}$ ). This suggests that the carbon crystallization is a relatively slow process which continues after the main reaction completion.

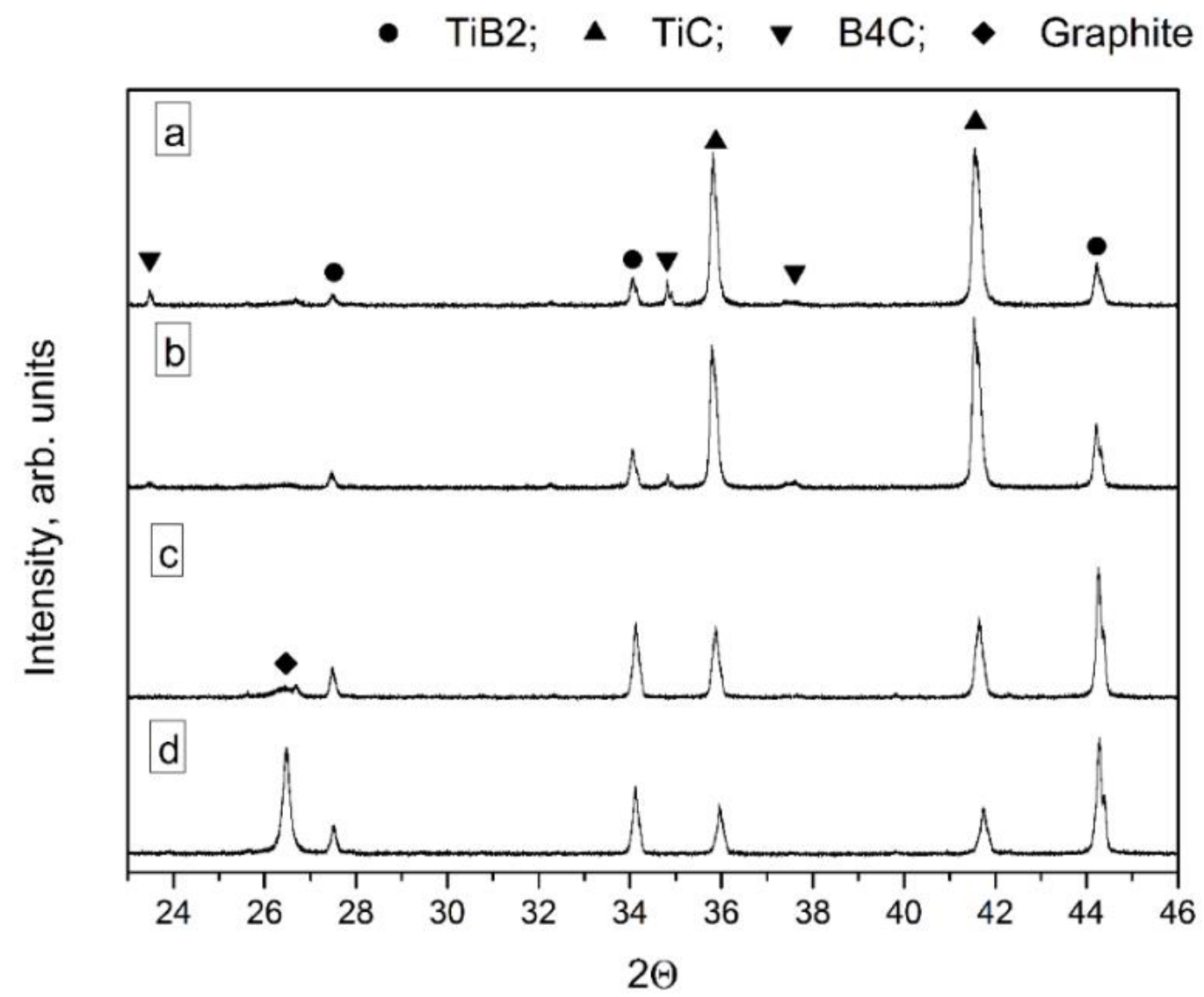


Fig.1. XRD of samples with rough $\mathrm{B}_{4} \mathrm{C}$ and excess $\mathrm{TiC}$ sintered at $1800^{\circ} \mathrm{C}$ for $2 \mathrm{~min}(\mathrm{a})$, $4 \min (b), 8 \min (\mathrm{c}), 16 \min (\mathrm{d})$ (samples \#1.1 - 1.4)

Fracture surface of sample number 1.2 (dwelling time $4 \mathrm{~min}$ ) is presented on Fig. 2. It shows large $(\sim 40 \mu \mathrm{m})$ dark appearing grains surrounded with little $(<5 \mu \mathrm{m})$ lighter ones. Element composition of the central dark cleavage (See Fig. 2) fairly corresponds to boron carbide. Line EDX elemental intensity profile analysis shows that boron content gradually decreases near the $\mathrm{B}_{4} \mathrm{C}$ grain indicating new-formed $\mathrm{TiB}_{2}$-based layer. Sharp peaks of carbon can be seen at the $\mathrm{B}_{4} \mathrm{C}$ area edges.

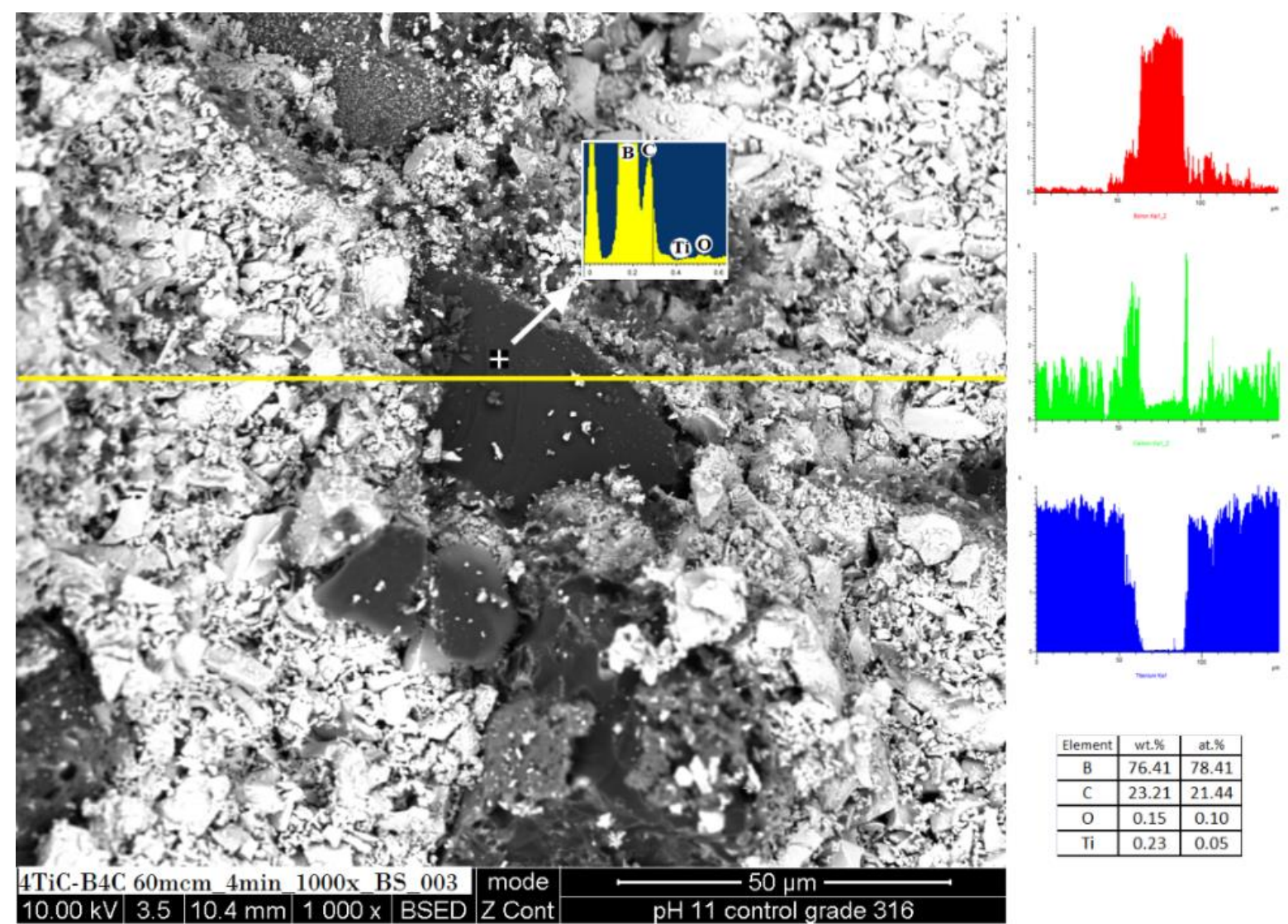

Fig. 2. BSE image of the fractured sample number 1.2 surface. The point EDX analysis spectra is shown with the quantification data table on the right. Elemental intensity profiles (boron, carbon and titanium) along the line on the right. 
EDX mapping of the boron carbide particle surface presented on Fig. 3, allows observing three types of different structures: (i) boron rich area, evidently revealing what remains of $\mathrm{B}_{4} \mathrm{C}$ grain; (ii) submicron Ti-rich objects embedded in $\mathrm{B}_{4} \mathrm{C}-$ which, considering the $\mathrm{XRD}$-analysis, are $\mathrm{TiB}_{2}$ nuclei; and (iii) carbon-rich foam-like (possibly amorphous) substance covering boron carbide. Hence, here we can see the initial stage, as shown in $[19,21]$, of $\mathrm{TiC}-\mathrm{B}_{4} \mathrm{C}$ reaction process, manifesting itself by boron transportation from $\mathrm{B}_{4} \mathrm{C}$ into titanium carbide. During this stage of sintering, the near surface layers mount up high concentration of B vacancies and in the end transform into foam-like carbon material. Some titanium atoms diffuse from TiC via the cover carbon and accumulate in the inner parts of the boron carbide grain. This results in titanium diboride nucleation inside the Fig. 3. BSE image of the fractured sample number 1.2 surface
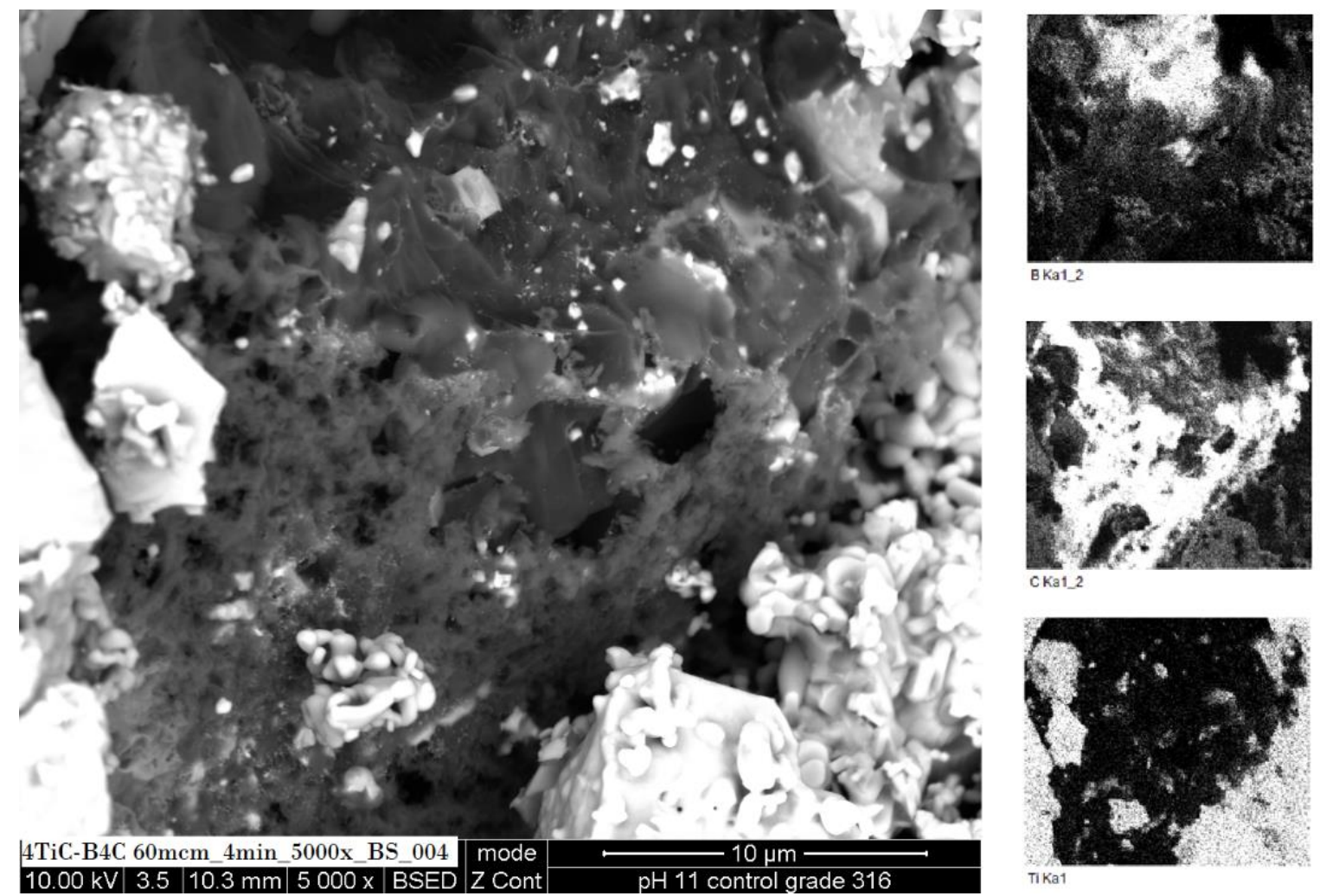

$\left(1800^{\circ} \mathrm{C}, 4 \mathrm{~min}\right)$. EDX elemental maps (boron, carbon and titanium) are shown on the right.

$\mathrm{B}_{4} \mathrm{C}$ crystals. 

body boron carbide grain size distribution does not affect the speed of decomposition. Fig. 4 presents a BSE image and EDX elemental maps of the powder mixture after 8min annealing (sample 1.3).
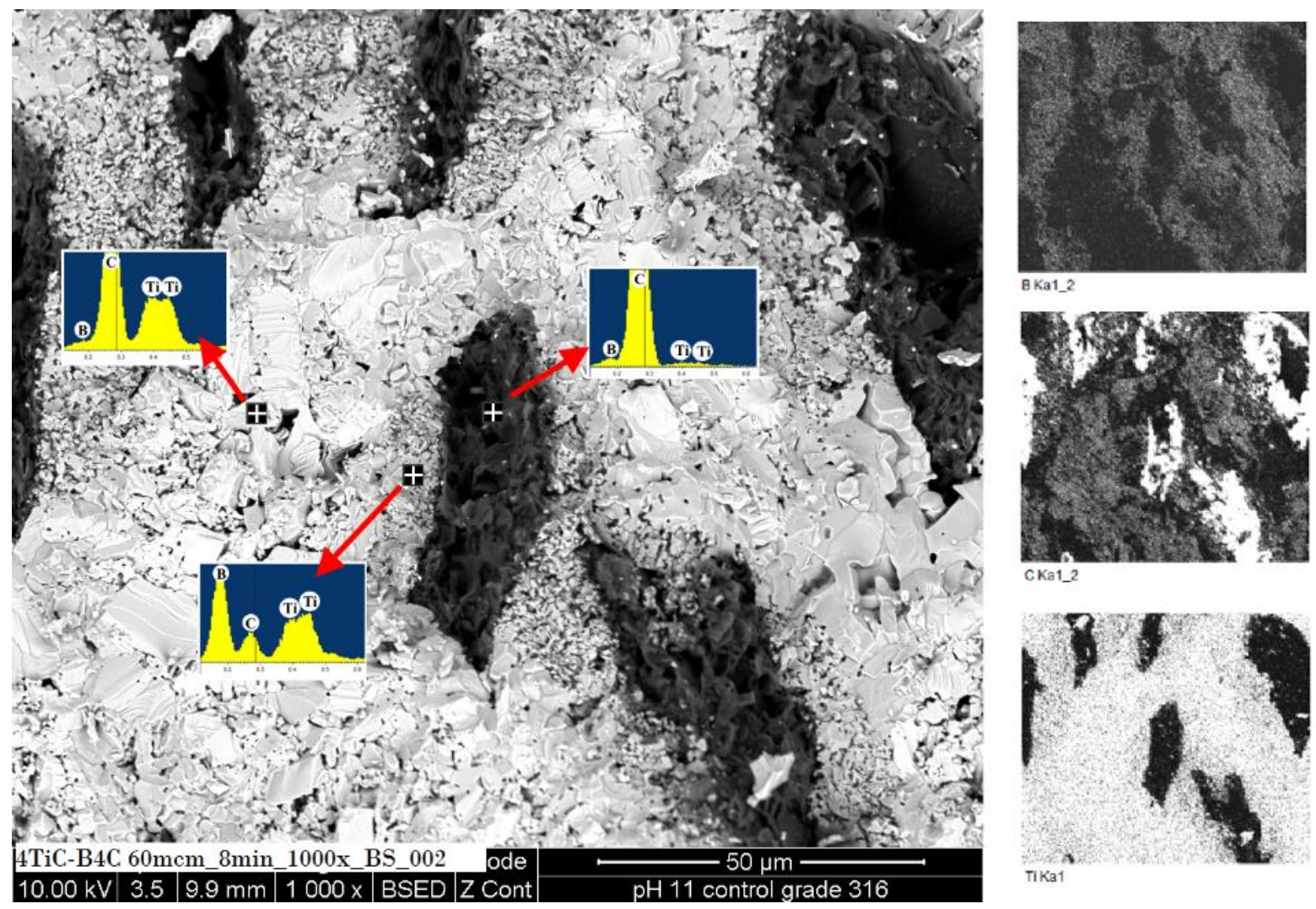

Fig. 4. BSE image of the fractured sample number 1.3 surface (sintering time $8 \mathrm{~min}$ ). EDX elemental maps (Boron, carbon and titanium) are shown on the right.

The observed material maps support the above statement and demonstrate three different phases: (i) carbon (dark grey, rather porous areas), (ii) titanium diboride containing considerable amount of carbon (grey areas surrounding carbon ones), and (iii) residual titanium carbide containing slight boron addition (light grey regions).

Considering the initial grain sizes, the large sponge-like carbon regions can only be leftovers of boron carbide grains. Small titanium diboride particles can be observed inside (See Fig. 4). Further sintering (for 16 min) leads to graphitization and partial densification of carbon sponges 
(See Fig. 1 and Fig. 5) alongside with segregation of graphite plates within new $\mathrm{TiB}_{2}$ grains (See Fig. 5 and the text below). Basing on the initial sizes of $\mathrm{B}_{4} \mathrm{C}$ grains $(\sim 70 \mu \mathrm{m})$, a sponge consists $1 / 2-1 / 3$ of the precursor crystal.

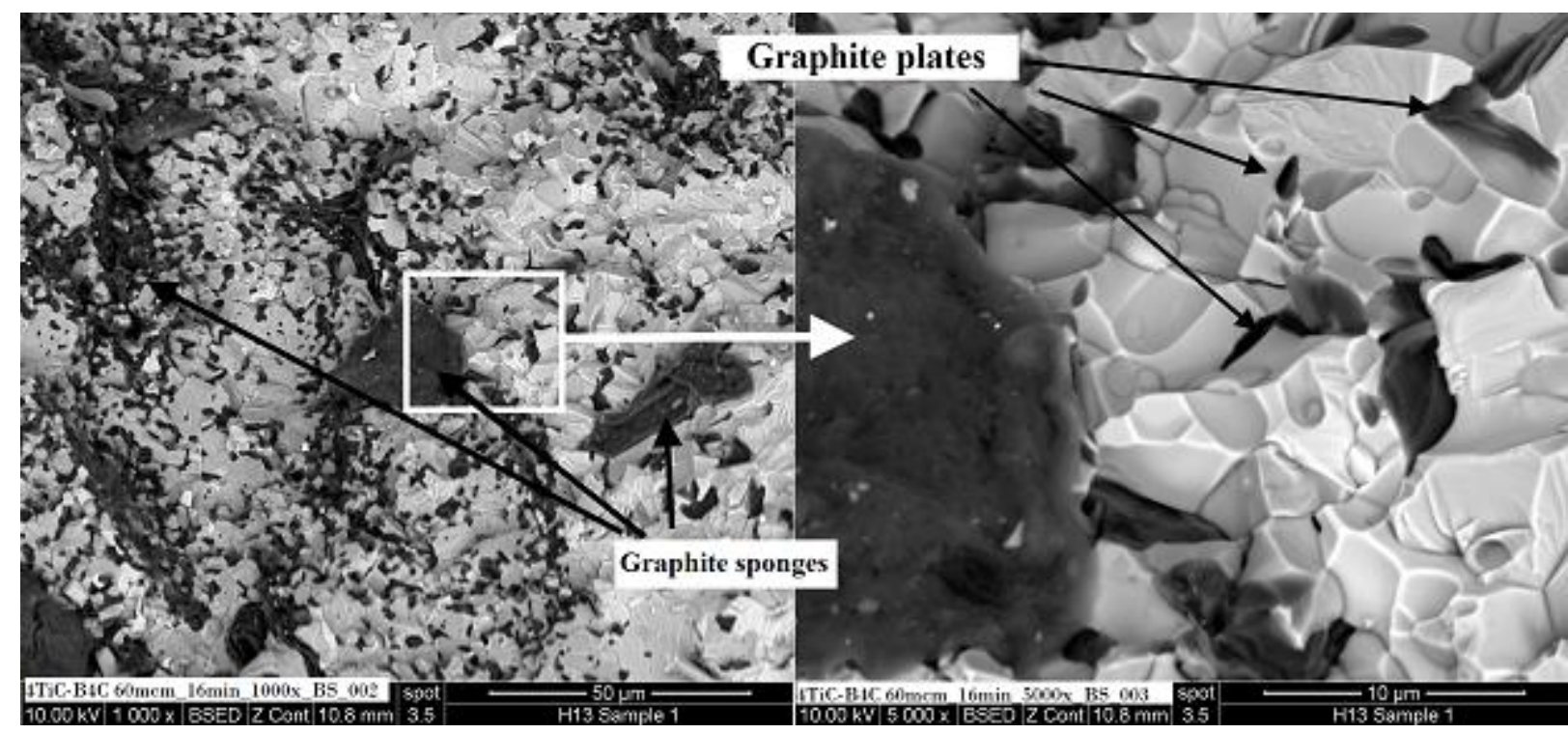

Fig. 5. BSE image of the fractured sample number 1.4 surface (sintering time 16 min). Two types of carbon: foam-like covering in place of grainy $\mathrm{B}_{4} \mathrm{C}$ leftovers and separate carbon plates within $\mathrm{TiB}_{2}$ grains.

It should be noted that fracture surfaces of the samples containing large boron carbide grains (See Fig. 2, 4, 5) show no faceted voids presented in [21]. The possible explanation of the fact could be as follows: boron carbide in samples $1.1-1.4$ was in deficiency. Thus, $\mathrm{B}_{4} \mathrm{C}$ crystals decomposed too fast and the voids did not have time to be formed by boron vacancy aggregation. To prove the statement, we produced additional sample sequence 3.1 - 3.4 (See Tab.1) with the excess of large $\mathrm{B}_{4} \mathrm{C}$ particles. The XRD pattern of sample 3.4 (Fig. 6) shows clear $\mathrm{B}_{4} \mathrm{C}$ peaks after 16 min sintering. 


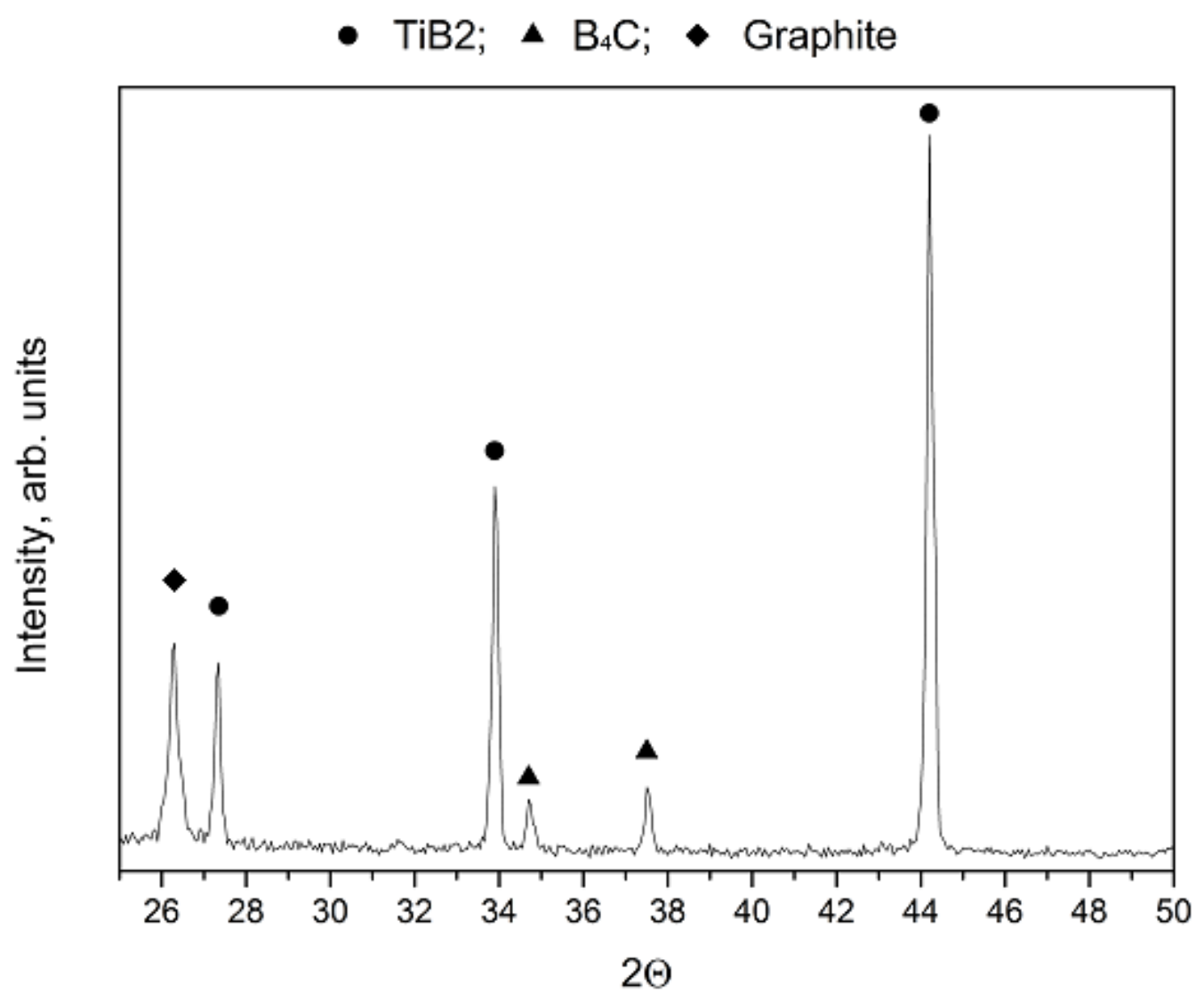

Fig. 6. XRD spectra of sintered for 16 min sample (sample 3.4)

As is shown on Fig.7 boron carbon contains fair amount of discussed faceted voids. Worth noting, that many of the voids contain tiny titanium diboride particles inside. 


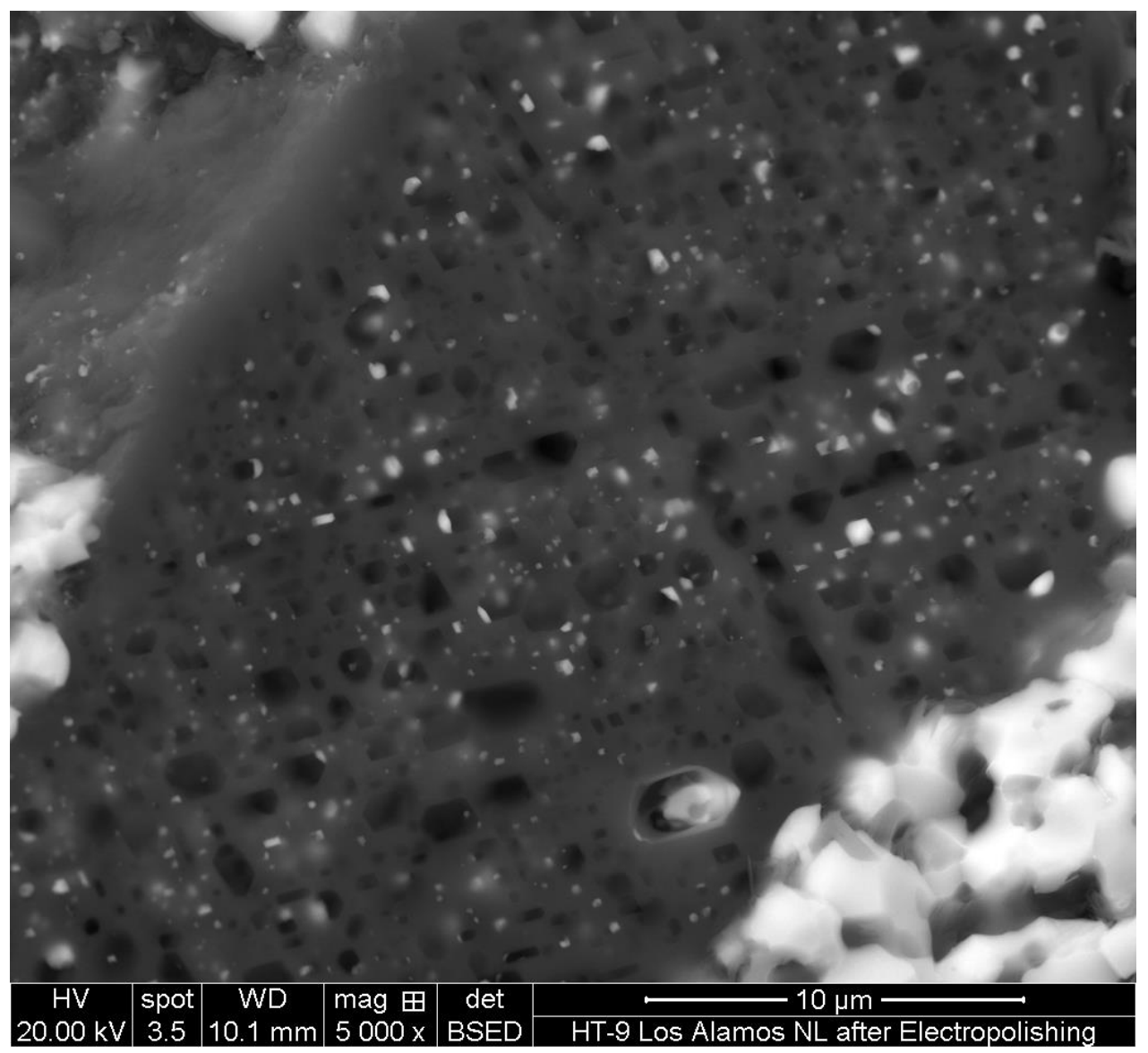

Fig. 7. BSE image of the fractured sample \# 3.4 surface (sintering time $16 \mathrm{~min}$ ).

\section{2. $\mathrm{TiC}$ to $\mathrm{TiB}_{2}$ transformation and graphite platelets precipitation}

So far, we investigated phenomena following the process of boron atoms leaving $\mathrm{B}_{4} \mathrm{C}$ crystals. The second part is to examine process of boron moving into the titanium carbide grains. For this we explored samples $2.1-2.4$ produced via hot pressing of large $(\sim 70 \mu \mathrm{m}) \mathrm{TiC}$ particles mixed with the excess of finely dispersed $(\sim 2 \mu \mathrm{m})$ boron carbide powder (See Tab. 1). 


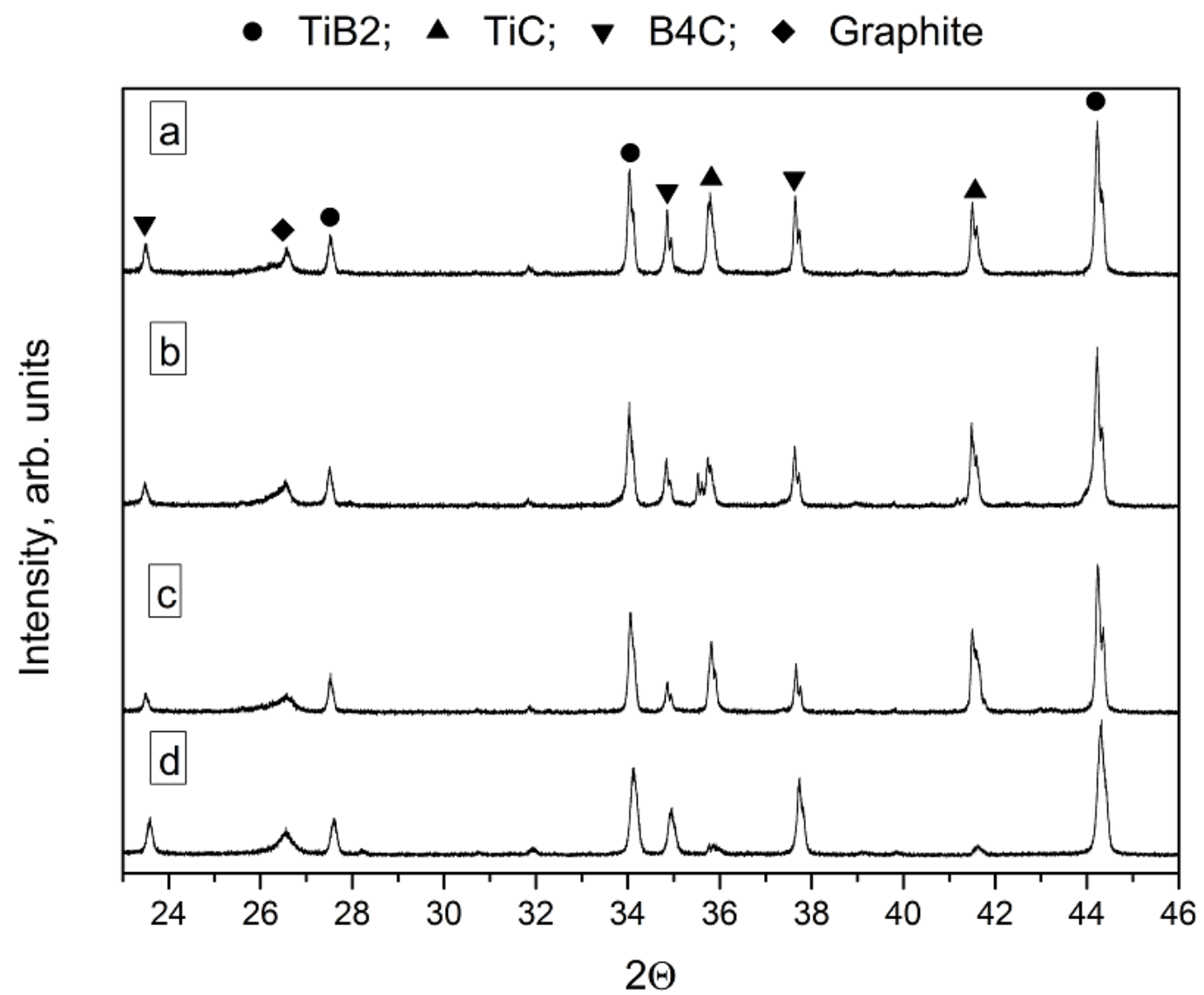

Fig. 8. XRD spectra of sintered samples with grainy $\mathrm{TiC}$ and excess of $\mathrm{B}_{4} \mathrm{C}$ in the green body. Sintering time at $1800^{\circ} \mathrm{C}: 2 \mathrm{~min}(\mathrm{a}), 4 \mathrm{~min}(\mathrm{~b}), 8 \min (\mathrm{c}), 16 \mathrm{~min}(\mathrm{~d}),($ samples $2.1-2.4$, Tab.1).

The evolution of sample phase composition (XRD data, Fig. 8) reflects, in general, the reaction (1) progression. SEM image of sample 2.1 fracture surface (see Fig. 9) shows formation of inhomogeneous reaction layer between $\mathrm{B}_{4} \mathrm{C}$ and $\mathrm{TiC}$ precursors after $2 \mathrm{~min}$ sintering. There are three different parts of the structure: The "outer" one (most remote from TiC bulk) containing roughly equiaxial submicron $\mathrm{B}_{4} \mathrm{C}$ grains, "middle" one consisted of elongated micron sized features, and the most porous "inner" one with seemingly amorphous phase. There are also visible planar defects in $\mathrm{TiC}$ near the grain border. 


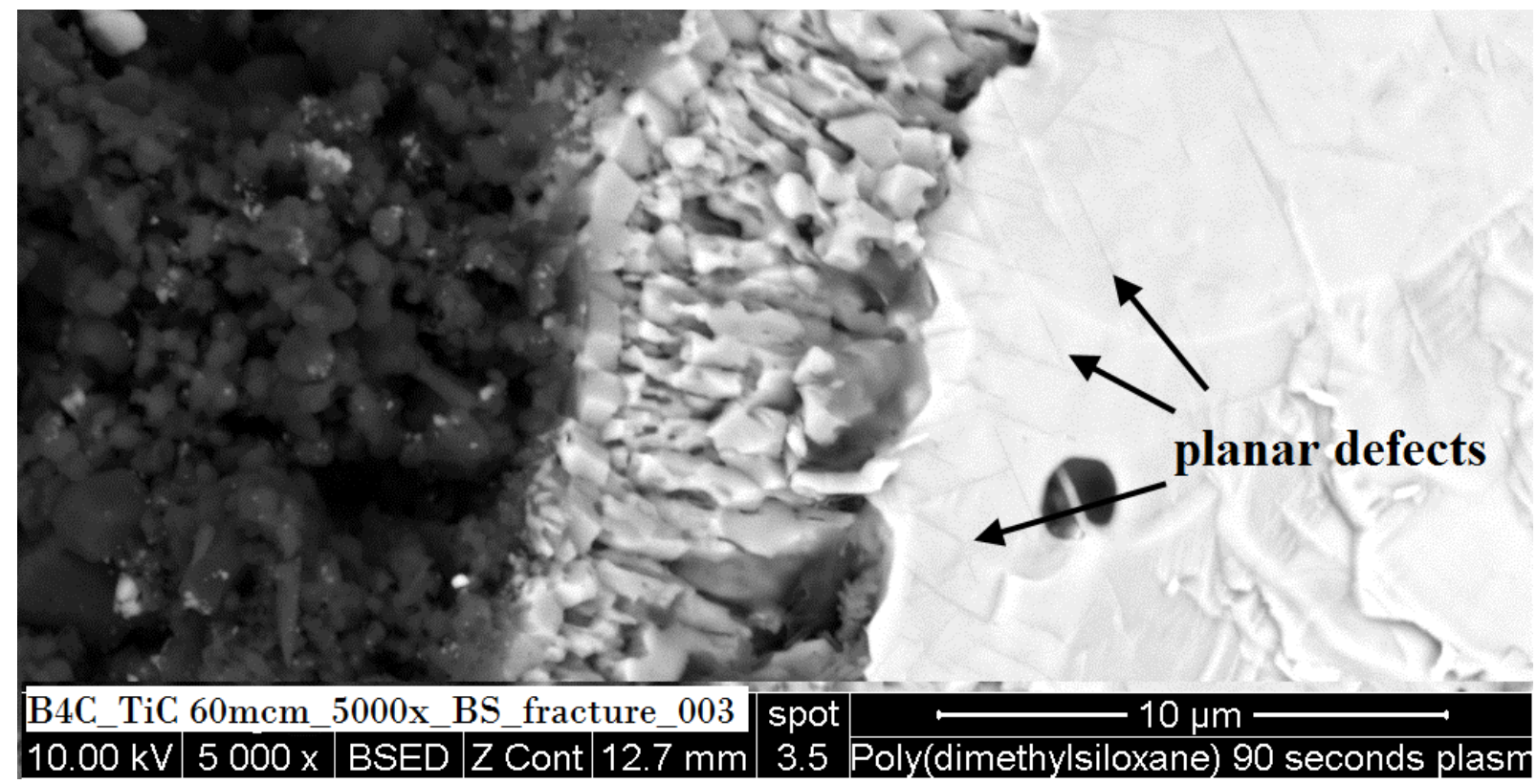

Fig. 9. BSE image of sample \# 2.1 fracture surface (sintering time $2 \mathrm{~min}$ ). $\mathrm{B}_{4} \mathrm{C}$ (dark grey) and $\mathrm{TiC}$ (light grey) precursors separated with Ti-B-C (grey) reaction layer

EDX analysis of the reaction layer (See Fig. 10) cannot be interpreted in terms of precise atomic composition of the explored areas (as the surface is not plain and grains are too small); however, it is evident that all the grains have substantial amounts of all main elements (carbon, boron and titanium). Hence, the observed reaction layer has neither carbon inclusions nor diboride particles and can be identified as a "proto-structure" of future $\mathrm{TiB}_{2}$ covering. Interestingly, that border TiC contains considerable amount of boron atoms (See Spectrum 3, Fig. 10) which should seemingly be connected to the reaction mechanisms. 


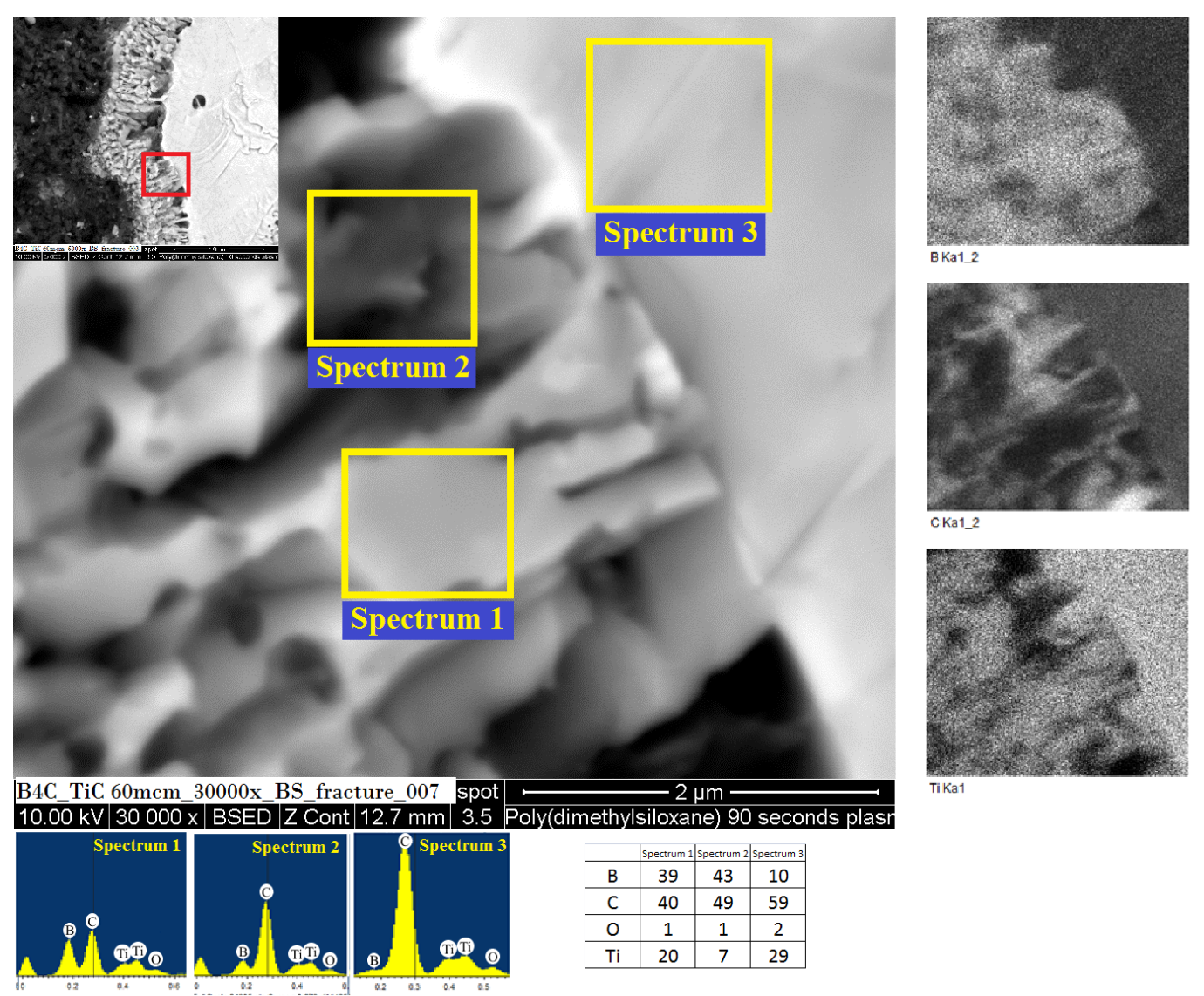

Fig. 10. BSE image of the fractured surface of sample 2.1 (sintering time $2 \mathrm{~min}$ ). The reaction layer. EDX elemental maps on the right.

Fracture surface of sample 2.3 sintered for 8 min (see Fig. 11) presents already formed continuous $\mathrm{TiB}_{2}$ layer (spectrum 2, Fig. 11) which separates $\mathrm{B}_{4} \mathrm{C}$ and $\mathrm{TiC}$ precursors. It should be noted that EDX analysis indicates no diffused titanium atoms inside the $\mathrm{B}_{4} \mathrm{C}$ grain while both titanium carbide and titanium diboride contain considerable amounts of boron and carbon respectively (See Tab. 2).

Table 2. EDX quantification data from the analysis spots of sample 2.3 (See Fig. 11)

\begin{tabular}{|c|c|c|c|}
\hline Spectrum \# & B, at.\% & C, at.\% & Ti, at.\% \\
\hline 1 & 78 & 22 & - \\
\hline 2 & 66 & 2 & 34 \\
\hline 3 & 6 & 45 & 49 \\
\hline
\end{tabular}



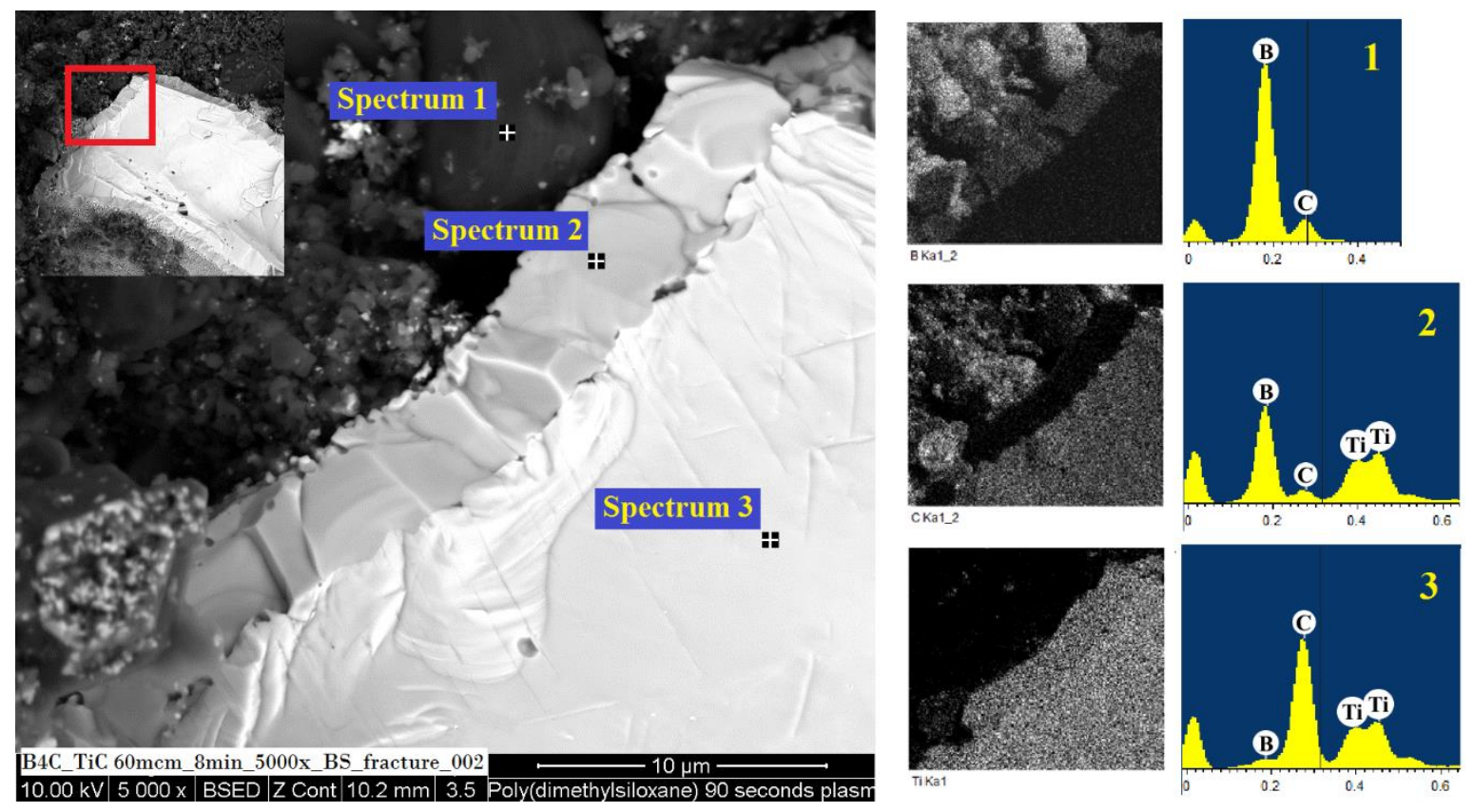

Fig. 11. BSE image of the fractured sample number 2.3 surface (sintering time 8 min). EDX elemental maps (boron, carbon and titanium) and EDX spectra from the distinctive areas (See Tab. 2) on the right.

Sintering of the precursor mixture for longer, for $16 \mathrm{~min}$ in total, results in further changes in the reaction area (see Fig. 12). Similarly to the 8 min sample 2.3, titanium diboride layer is solid and has the same thickness $(\sim 6 \mu \mathrm{m})$ which indicates that $\mathrm{TiB}_{2}$ formation mostly accomplished during first 8 minutes of the sintering. However, as opposed to sample 2.3, 16 min sintering led to formation of carbon inclusions in $\mathrm{TiB}_{2}-\mathrm{TiC}$ interface. The carbon inclusions have platelet shape and could only origin from consolidation of $\mathrm{TiC}$ grain carbon being replaced with boron atoms in the reaction region. 

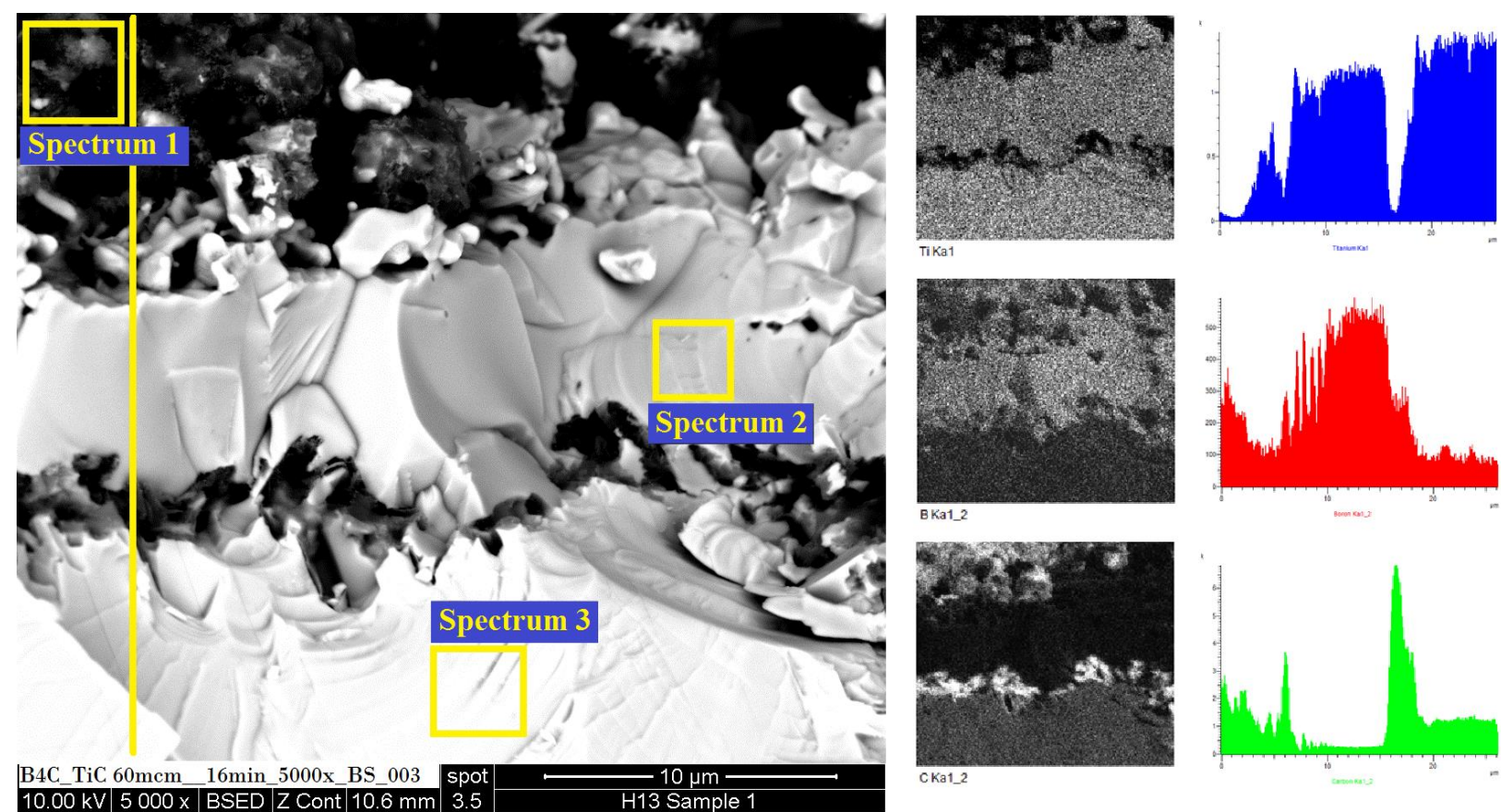

TiKa1
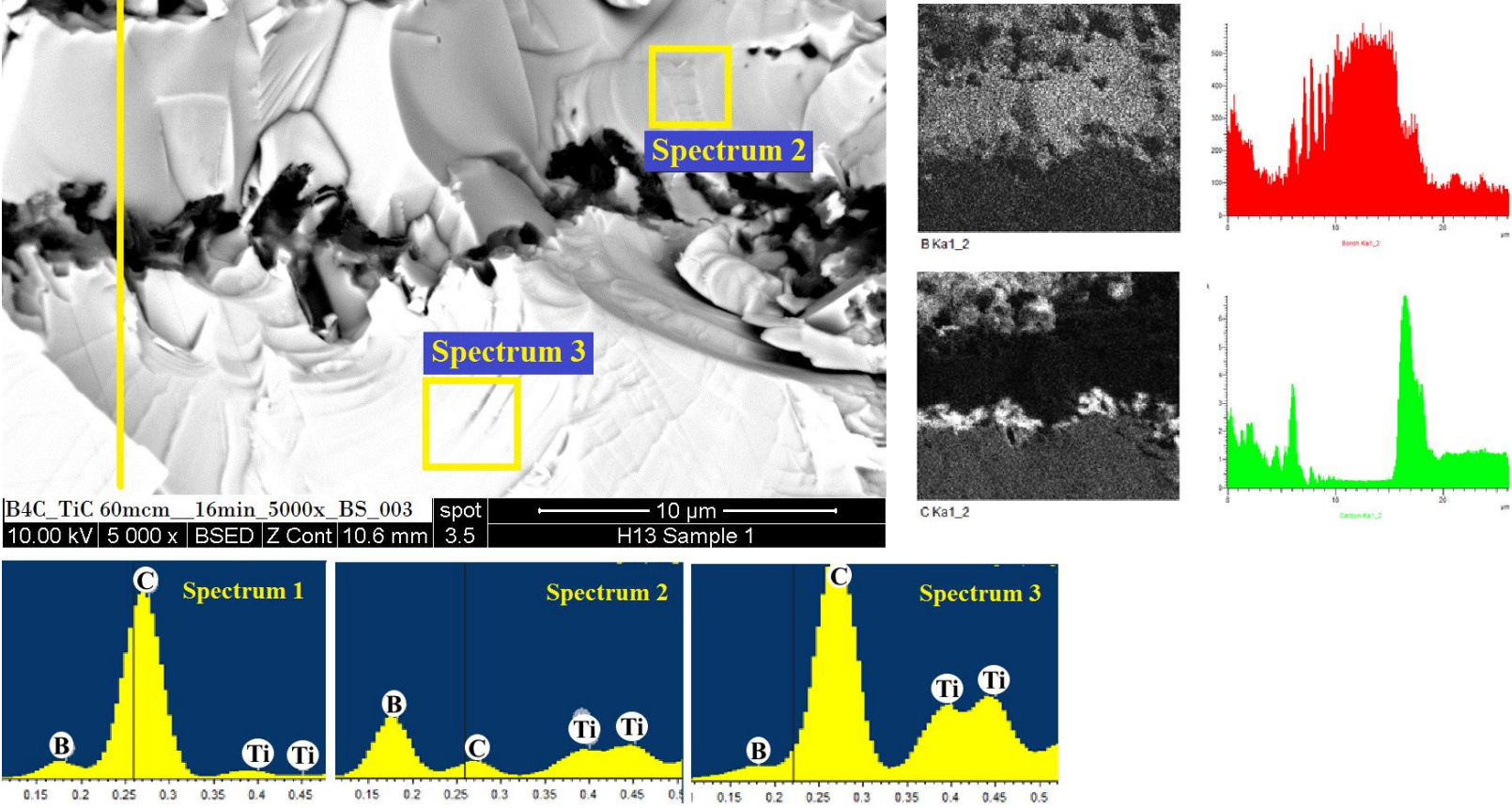

Fig. 12. BSE image of the fractured sample number 2.4 surface (sintering time $16 \mathrm{~min}$ ). Image of TiC- $\mathrm{B}_{4} \mathrm{C}$ reaction layer. EDX elemental maps and EDX elemental intensities along the line are on the right.

\section{Discussion}

As has been shown earlier $[19,21]$, TiC-B ${ }_{4} \mathrm{C}$ high temperature reaction starts with boron evaporation from boron carbide surface. It can be seen from Fig. 3 that such boron depletion of $\mathrm{B}_{4} \mathrm{C}$ near-surface layer converts it into carbon-based foam. The foam, having a high amount of extra fine vacancies and pores, provides a high permeability media for sublimated boron efficient transfer from the inner areas of $\mathrm{B}_{4} \mathrm{C}$ crystals and enables the reverse diffusion of Ti-atoms. Further association of B-vacancies leads to formation of submicron faceted voids inside the remnant $\mathrm{B}_{4} \mathrm{C}$ (See Fig. 7). Great Ti diffusion fluxes cause its essential concentration gradients inside the 
decomposing $\mathrm{B}_{4} \mathrm{C}$ phase. As it is shown in [24], such gradients strongly affects the incubation time of new phase nucleation. That is why the $\mathrm{TiB}_{2}$ particles do not appear near $\mathrm{TiC}$ interfaces (where the concentration of titanium atoms is higher). It looks like that the void surface provides best energy opportunity for the titanium diboride formation (See Fig. 7).

In case of no boron carbide excess (regarding the stoichiometry of $\mathrm{TiC}: \mathrm{B}_{4} \mathrm{C}=2: 1$ ), the boron depletion at last turns $\mathrm{B}_{4} \mathrm{C}$ grains into carbon-based sponge-like areas with tiny $\mathrm{TiB}_{2}$ particles inside (Fig. 4).

Titanium diboride forming on TiC grain surface could, in principle, create a diffusion barrier for further atomic exchange between the precursors. For instance, Schmidt and Borchardt [25] showed that the diffusivity of boron in $\mathrm{TiB}_{2}$ obeys Arrhenius' law, with an activation energy of $2.2 \mathrm{eV}$ and a preexponential factor of $4 \cdot 10^{-12} \mathrm{~m}^{2} / \mathrm{s}$. Considering sample 2.3 annealing parameters $\left(\mathrm{t}=8 \mathrm{~min}\right.$ and $\left.\mathrm{T}=1800{ }^{\circ} \mathrm{C}\right)$, the value of diffusion length $\left(\mathrm{L}=2(\mathrm{Dt})^{1 / 2}\right)$ is $\sim 250 \mathrm{~nm}$ which is at least one order less than $\mathrm{TiB}_{2}$ covering thickness (See Fig. 11). On the other hand, Fan et al [26] reported the diffusion energy barrier of $\mathrm{B}$ in $\mathrm{TiC}$ to be $0.84 \mathrm{eV}$ along (001) plain and $0.69 \mathrm{eV}$ along (111), thus boron atoms migration in titanium carbide can be several orders of magnitude greater.

Vekables [27] and Chien et al [28] showed that the "trace" boron concentration in titanium carbide initiates precipitation of $\mathrm{TiB}_{2}$ platelets along (111) plane of $\mathrm{TiC}$ lattice. The $\mathrm{TiB}_{2}$ platelets [27] had $\sim 1 \mathrm{~nm}$ thickness and $\sim 0.5 \mu \mathrm{m}$ length, which are too small to be identified by SEM themselves, however the precipitate traces are possibly seen as already mentioned TiC planar defects close to reaction area (see Fig. 9). It is worth noting that titanium planes in $\mathrm{TiB}_{2}$ (Fig. 13a) are quite similar to $\mathrm{Ti}$ (111) in TiC (Fig. 13b). From that point of view, to convert NaCl-type structure of $\mathrm{TiC}$ into hexagonal structure of $\mathrm{TiB}_{2}$, one need to: (i) replace carbon atoms with boron; (ii) place boron into interstitials (blank circles on Fig. 13b); (iii) shift Ti plates. It is well known $[28,29]$, that titanium carbide is always carbon deficient (from 2 to $40 \%$ of the carbon atoms are absent in TiC crystals), thus the first step can start with migrating boron being captured in the 
carbon vacancies. To make first step in understanding of TiC lattice behavior in the case of boron accumulation along (111) planes we employed computer modelling.

a

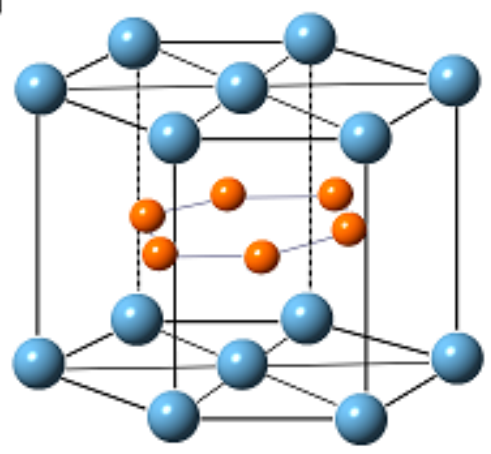

b

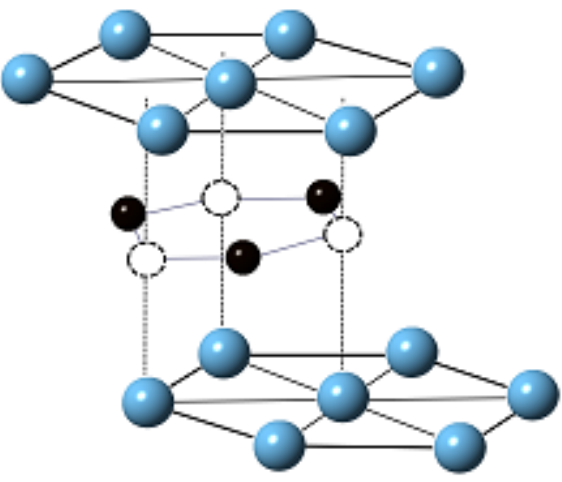

Fig 13. Titanium diboride (a) and titanium carbide (b) lattices. Empty circles mark interstitial positions

\section{Ab initio calculations}

A supercell containing 24 atoms: three (111) layers (close-packed ABC structure) by four titanium atoms and corresponding carbon ones, was chosen for the analysis (See Fig. 14a).

Three boron atoms were incorporated into the supercell in two different ways. In the first case, three boron atoms were placed in carbon substitution positions, in the second case, two B substituted $\mathrm{C}$ and the third $\mathrm{B}$ was placed in the interstitial position, in correspondence to $\mathrm{TiB}_{2}$ lattice. 


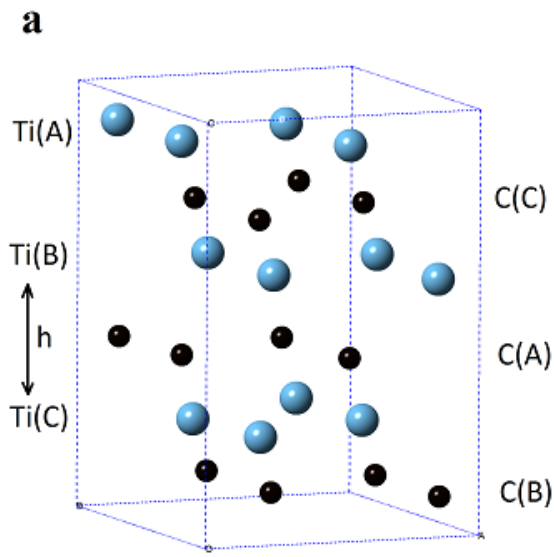

b

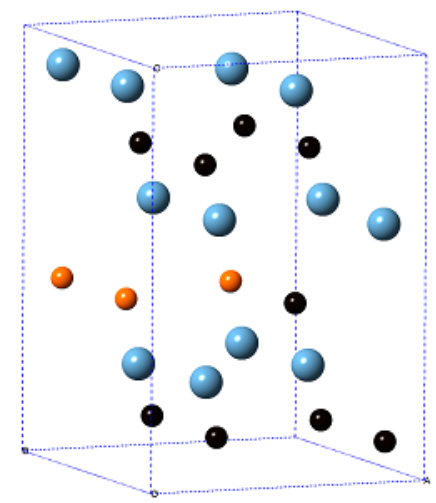

c

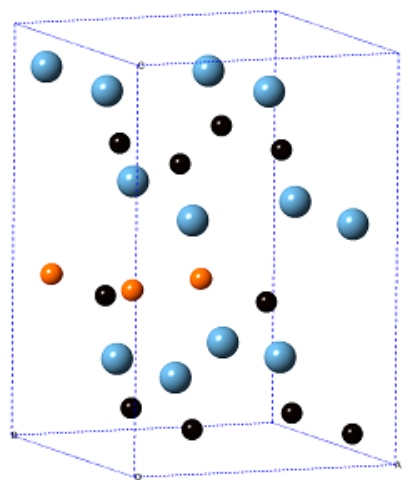

Fig. 14. TiC-based supercell with boron dope ( $\mathrm{Ti}$ - blue, $\mathrm{C}$ - black, and $\mathrm{B}$ - orange). Three (111) titanium layers (close-packed $\mathrm{ABC}$ structure) with corresponding carbon ones (a); three boron atoms substitute carbon (b); two boron atoms substitute the carbon ones and one boron is situated in the interstitial position (c).

When boron atoms where incorporated into the supercell, the lattice relaxation was simulated according to forces calculated from the first principles. As is evident from Fig. 15, an equilibrium interplanar spacing between adjacent (111) Ti layers rises by $8 \%$ in the case of three carbon atoms being substituted with three boron ones (Fig. 14b), and by $10.5 \%$ if two boron atoms substitute carbon and one is situated in the interstitial position (Fig. 14c). 


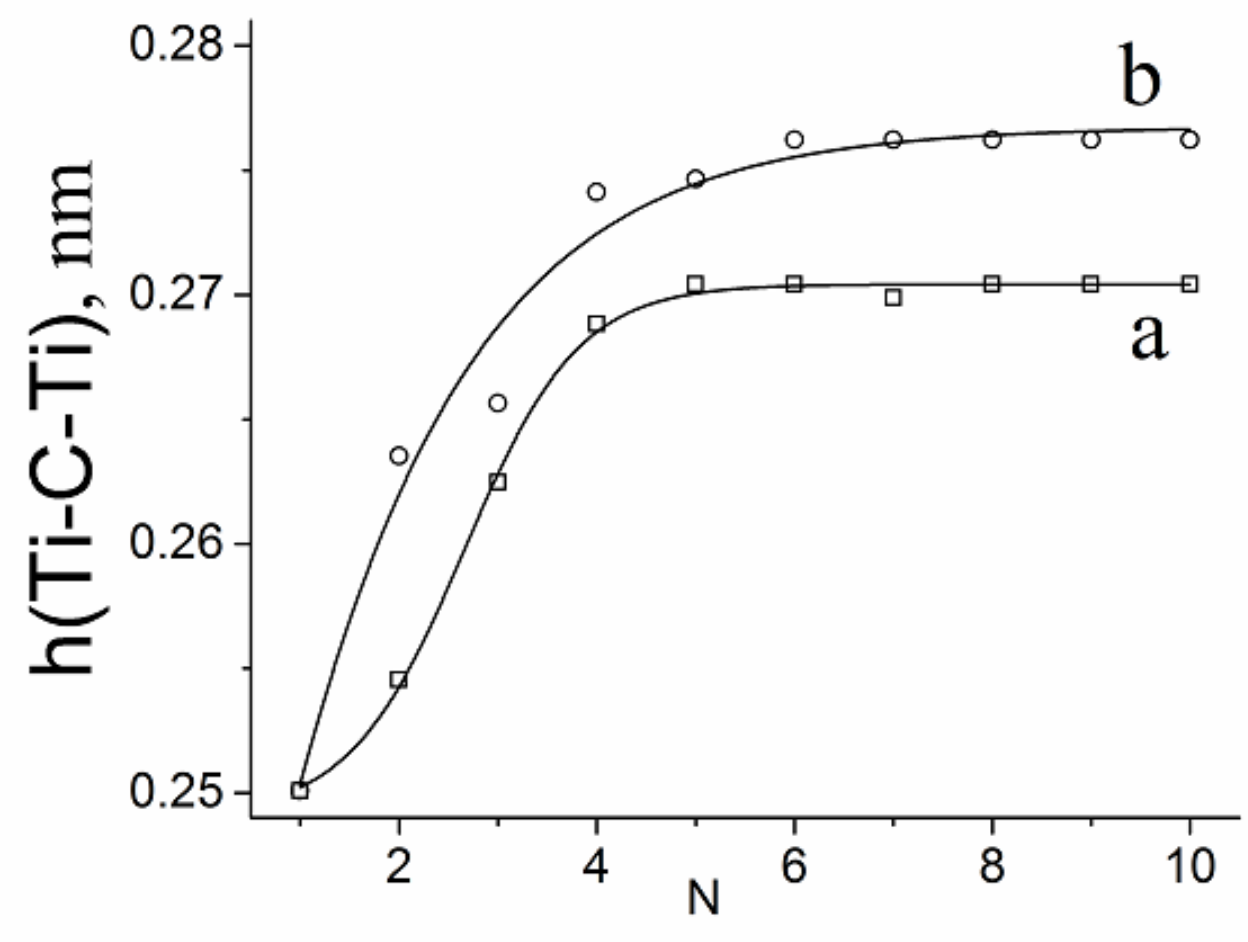

Fig. 15. The change in spacing between adjacent Ti layers after $\mathrm{N}$ steps of the lattice relaxation simulated with three B atoms incorporated into the supercell: (a) all the boron atoms replace carbon; (b) two boron atoms replace carbon, and the third one is in the interstitial position.

Therefore, boron atoms being captured by carbon vacancies lead to increase in the distance between (111) planes in $\mathrm{TiC}$ and this process possibly increases the probability of further boron incorporation into $\mathrm{TiC}$ lattice and leads to $\mathrm{TiB}_{2}$ formation. Nucleating $\mathrm{TiB}_{2}$ platelets, with $\mathrm{Ti}(111)$ interplanar spacing $28 \%$ greater than that of $\mathrm{TiC}$, produce substantial tensile stresses, while the displaced carbon concentrates in $\mathrm{TiC}^{-\mathrm{TiB}_{2}}$ interface and weakens it. At the certain level, the stresses fracture TiC grain, chipping off newly formed titanium diboride grains.

Fig. 16 shows an image of cleaved titanium carbide grain near $\mathrm{TiB}_{2}$ border. Two faceted pits can be clearly seen on the cleavage surface. It is well known that the cubic crystals are the weakest along (100) set of planes. Therefore, considering the cleavage surface corresponds (100) direction, 
the mentioned pits reveal (111) planes and illustrate the $\mathrm{TiC}$ grain weakened by the formed $\mathrm{TiB}_{2}$ platelets.

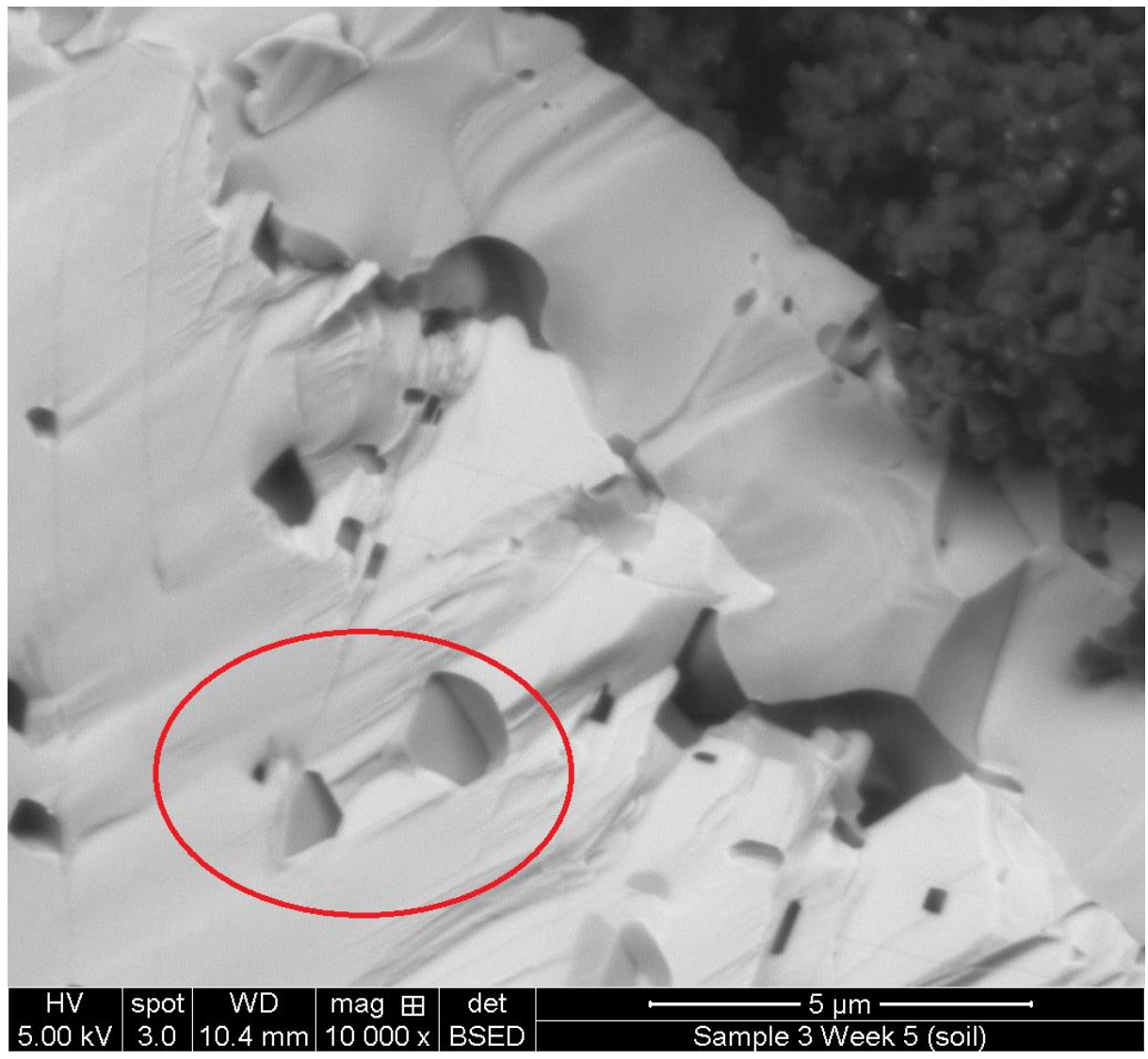

Fig. 16. BSE image of fracture surface of $\mathrm{TiC}$ grain (white) surrounded with $\mathrm{TiB}_{2}$ (gray) with faceted pull-outs (sample 2.3). 

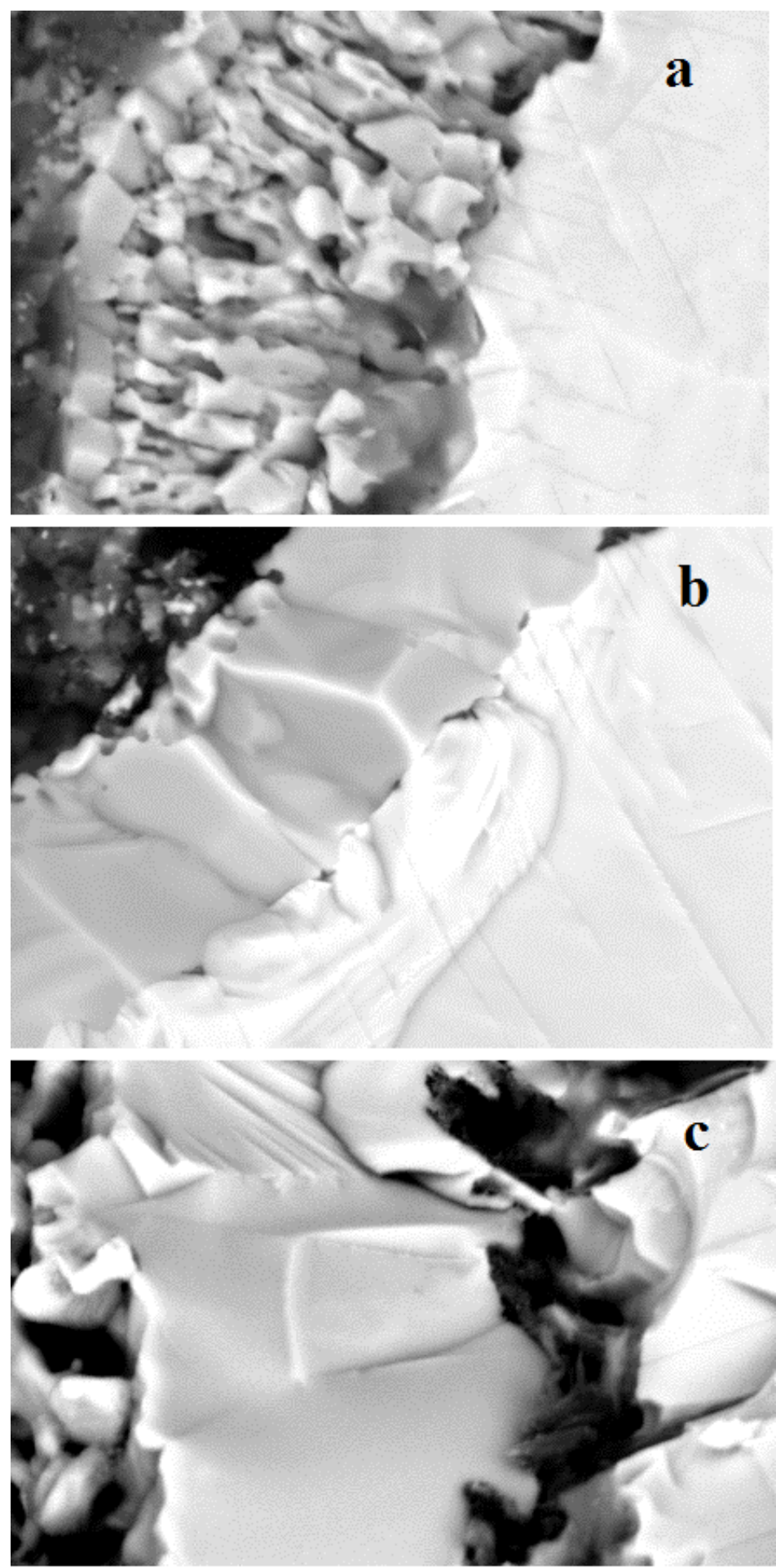

Fig. 17. BSE image of fracture surfaces. TiC-B ${ }_{4} \mathrm{C}$ reaction layer after $2 \mathrm{~min}(\mathrm{a}), 8 \mathrm{~min}(\mathrm{~b})$ and $16 \mathrm{~min}(\mathrm{c})$ sintering at $1800^{\circ} \mathrm{C}$ (samples $2.1,2.3,2.4$ ).

Therefore, as growing $\mathrm{TiB}_{2}$ nuclei fracture TiC crystals, $\mathrm{B}$ via $\mathrm{TiB}_{2}$ solid-state diffusion can no longer limit the conversion reaction: the sublimated boron diffuses through porous Ti-B-C reaction structure (See Fig. 17a) and condenses on the fresh TiC surfaces. Further sintering leads 
to quick densification of initial reaction area due to external pressure and additional reaction heat release (Fig. 17b).

Some carbon atoms remain inside the consolidated diboride layer. As is shown in [20], equilibrium $\mathrm{C}$ in $\mathrm{TiB}_{2}$ concentration, which cannot exceed 2 at. $\%$ even at $2500^{\circ} \mathrm{C}$, is negligible at $1800^{\circ} \mathrm{C}$. Therefore, remaining carbon precipitates after 16 min sintering near $\mathrm{TiB}_{2}$ border forming submicron graphite plates on $\mathrm{TiC}_{-} \mathrm{TiB}_{2}$ interface (Fig. 17c).

\section{Conclusions}

The reactive high temperature structure formation of $\mathrm{TiB}_{2}-\mathrm{C}$ based heteromodulus ceramics starts with boron carbide grain surfaces loosing boron via sublimation. Such boron outdiffusion produces a great number of vacancies and vacancy clusters, which create carbon-rich foam. The carbon foam has high diffusion permeability, which allows further boron transport from inside the grain to the surface as well as titanium influx. The process continues until $\mathrm{B}_{4} \mathrm{C}$ precursor grains fully transform into the sponge-like graphite volumes with some tiny $\mathrm{TiB}_{2}$ inclusions. Sponge sizes are approximately $1 / 3$ of the precursor boron carbide particles.

Sublimated boron deposits on all the $\mathrm{TiC}$ grains and diffuses inside, leading initially to $\mathrm{TiB}_{2}$ platelets precipitation. The platelets growth generates high level of tensile stresses resulting in TiC grain chipping. This creates porous structure of the reaction layer and allows sublimated boron depositing on fresh $\mathrm{TiC}$ surfaces.

Quick densification of the initial reaction area because of the external pressure prevents further reaction progress at approximately $6 \mu \mathrm{m}$ of $\mathrm{TiB}_{2}$ layer thickness. Carbon captured inside the solid diboride layer precipitates after 16 min sintering in the form of submicron graphite platelets in $\mathrm{TiC}_{-} \mathrm{TiB}_{2}$ interfaces. 


\section{References}

1. W. D. Kingery, Factors Affecting Thermal Stress Resistance of Ceramic Materials, J. Am. Ceram. Soc. 38 (1) (1955) 1-13.

2. I. L. Shabalin, Y. Wang, A. V. Krynkin, O. V. Umnova, V. M. Vishnyakov, L. I. Shabalin and V. K. Churkin, Physicomechanical properties of ultrahigh temperature heteromodulus ceramics based on group 4 transition metal carbides, Adv. Apl. Ceram. 109 (7) (2010) 405-416.

3. D. P. H. Hasselman, P. F. Becher and K. S. Mazdiyasni, Analysis of the Resistance of High-E, Low-E Brittle Composites to Failure by Thermal Shock, Werkstofftech. 11 (1980) 82-92.

4. Xiuqing Li, Yimin Gaon, Wu Pan, Xin Wang, Liancheng Song, Zhichao Zhong, ShanshanWu, Fabrication and characterization of B4C-based ceramic composites with different mass fractions of hexagonal boron nitride, Ceram. Int. 41 (2015) 27-36.

5. Takafumi Kusunose, Tohru Sekino, Yong-Ho Choa, and Koichi Niihara, Machinability of Silicon Nitride/Boron Nitride Nanocomposites, J. Am. Ceram. Soc., 85 (11) (2002) 2689-95

6. Lian Gao, Xihai Jin, Jingguo Li, Yaogang Li, Jing Sun, BN/Si3N4 nanocomposite with high strength and good machinability, Mater. Sci. Eng. A 415 (2006) 145-148.

7. D. John, G. M. Jenkins, Hot-working and strengthening in metal carbide-graphite composites, J. Mater. Sci. 21 (1986) 2941-2958.

8. Igor L. Shabalin, David M. Tomkinson, Leonid I. Shabalin, High-temperature hotpressing of titanium carbide - graphite hetero-modulus ceramics, J. Eur. Ceram. Soc., 27 (2007) 2171-2181.

9. Tao Jiang, Zhihao Jin, Jianfeng Yang, Guanjun Qiao, Mechanical property and $R$-curve behavior of the B4C/BN ceramics composites, Mater. Sci. Eng. A 494 (2008) 203-216.

10. G.J. Zhang, M. Ando, J.F. Yang, T. Ohji, Reaction synthesis of ceramic composites containing in situ formed boron nitride as dispersed phase, Key Eng. Mater. 247 (2003) 117-120. 
11. I.F.Kazo, A. Yu. Popov, Mechanical properties of $\mathrm{TiB}_{2}-\mathrm{TiC}-\mathrm{C}^{*}$ ceramic materials, Functional Materials 3 (2003) 503-506.

12. Wei-Ming Guo, Yang You, Guo-Jun Zhang, Shang-Hua Wu, Hua-Tay Lin, Improvement of fracture toughness of $\mathrm{ZrB} 2-\mathrm{SiC}$ composites with carbon interfaces, J. Eur. Ceram. Soc., 35 (2015) 1985-1989.

13. S.M. Asl, M.J. Zamharir, Z. Ahmadi, S. Parvizi, Effects of nano-graphite content on the characteristics of spark plasma sintered ZrB2-SiC composites, Int. J. Refract. Metals Hard Mater. $716(2018) 99-106$.

14. S. Parvizi, Z. Ahmadi, M.J. Zamharir, M.S. Asl, Synergistic effects of graphite nanoflakes and submicron $\mathrm{SiC}$ particles on the characteristics of spark plasma sintered $\mathrm{ZrB} 2$ nanocomposites, Int. J. Refract. Met. Hard Mater. 75 (2018) 10-17.

15. M.S. Asl, B. Nayebi, A. Zohre, M.J. Zamharir, M. Shokouhimehr, Effects of carbon additives on the properties of ZrB2-based composites: a review, Ceram. Int. 44 (7) (2018) 73347348.

16. S. V. Chornobuk, A. Yu. Popov, V. A. Makara, Structure and mechanical properties of reaction-sintered ceramic composite materials based on titanium and hafnium diborides. $\mathrm{J}$. Superhard Mater. 31 (2) (2009) 86-88.

17. R. Saggar, H. Porwal, P. Tatarko, I. Dlouhy and M. J. Reece, Boron nitride nanosheets reinforced glass matrix composites, Adv. Apl. Ceram. 114 (2015) 26-33.

18. O. Popov and V. Vishnyakov. Fracture toughness in some hetero-modulus composite carbides: carbon inclusions and voids, Adv. Apl. Ceram. 116 (2017), 61-70.

19. Oleksii Popov, Alexandra Klepko, Edward Lutsak, The influence of high pressure on TiC-B4C reaction kinetics, Int. J. Refract. Met. Hard Mater. 75 (2018), 234-237.

20. Rudy, E., Windisch, S., Ternary Phase Equilibria in Transition Metal - Boron - Carbon -Silicon Systems, Tech. Rep. No. AFML-TR-65-2, Part II, Vol. XIII (1966). 
21. O. Popov, S. Chornobuk, V. Vishnyakov, Structure formation of TiB2-TiC-B4C-C hetero-modulus ceramics via reaction hot pressing, Int. J. Refract. Met. Hard Mater. 64 (2017) 106-112.

22. X. Gonzea, B. Amadond, P.M. Angladee, J.M. Beukena, F. Bottind, P. Boulangera, F. Brunevalq, D. Calistej, R. Caracasl, M. Côtéo, T. Deutschj, L. Genovesei, Ph. Ghosezk, M. Giantomassia, S. Goedeckerc, D.R. Hamannm, P. Hermetp, F. Jolletd, G. Jomardd, S. Lerouxd, M. Mancinid, S. Mazevetd, M.J.T. Oliveiraa, G. Onidab, Y. Pouillona, T. Rangela, G.M. Rignanesea, D. Sangallib, R. Shaltafa, M. Torrentd, M.J. Verstraetea, G. Zerahd, J.W. Zwanzigerf, ABINIT: First-principles approach to material and nanosystem properties, Computer Phys. Comm., 180 (12) (2009) 2582-2615.

23. I. V.Plyushchay, T. L.Tsaregrads'ka, O. O.Kalenyk, O. I.Plyushchay, The Theoretical Analysis of Phase-Formation Processes in Amorphous Alloys of Fe-Zr System. Metallofiz. Noveishie Tekhnol., 38 (9) (2016) 1233-1247.

24. A. M. Gusak, F. Hodaj and A. O. Bogatyrev, Kinetics of nucleation in the concentration gradient, J. Phys.: Cond. Mat. 13 (12) (2001) 2767-2787.

25. H. Schmidt and G. Borchardt, Self-diffusion of boron in TiB2, J. Appl. Phys. 93 (2) (2003) 907-911.

26. Xiaoliang Fan, Haimin Ding, Kaiyu Chu, The influence of boron on the adsorptionof Ti and C on TiC surfaces, Mater. Sci.-Poland, 32 (1) (2014) 112-120.

27. John D. Vekables, The nature of precipitates in boron-doped TiC, Phil. Magazine. 16 (143) (1967) 873-890.

28. F.-R. Chien, S. R. Nutt \& D. Cummings, Defect structures in single crystal TiC, Adv. Apl. Ceram. 68 (2) (1993), 325-348.

29. Q. Zhao, J. Wu, A. Chaddha, H. Chen, J. Parsons, \& D. Downham, Defect structure in single crystal titanium carbide, J. Mater. Res. 9(8) (1994) 2096-2101. 